\title{
NOSSA SENHORA E OS CORPOS CELESTES: A TRADICÁO IMAGÉTICA CATÓLICA NO MUNDO DA MODA E DAS CELEBRIDADES
}

\author{
Patricia Machado*
}

INTRODUÇÃO

Este ensaio que trata da simbologia católica no universo da moda, mais especificamente, da imagem de Nossa Senhora como ícone fashion presente em algumas expressões da cultura midiática contemporânea, incluindo o mundo das chamadas "celebridades". Para tanto, buscaremos refletir sobre as expressões imagéticas e imaginárias que envolvem a representação da religião na mídia.

Nosso olhar será direcionado aos processos comunicacionais presentes na festa de lançamento da edição 2018 da exposição do Instituto de Moda do Metropolitan Museum em Nova Iorque (EUA). Denominada Heavenly Bodies: Fashion and the Catholic Imagination (Corpos Celestes: Moda e Imaginação Católica), a exposição de arte aconteceu no Cloisters - o museu de arte sacra do Met e contou com o apoio do Vaticano, além do empréstimo de 40 itens históricos que são parte do acervo do Pontífice Conselho de Cultura e também com inserção de peças de artistas e designers de moda contemporâneos.

Daremos também atenção ao evento de abertura da exposição - o Met Gala 2018. O baile, organizado pela diretora da Vogue americana, Anna Wintour, teve uma ampla cobertura da imprensa especializada e também foi objeto de milhares de postagens - positivas e negativas - nas mídias sociais.

Inúmeras celebridades, vestidas com roupas inspiradas na simbologia e ícones católicos, desfilaram pelo tapete vermelho do evento. A imagem, os símbolos e a iconografia de Nossa Senhora foram tema das roupas de artistas (fig. 1), tais como: Madonna, Lilly Collins, Lana Del Rey e Kim Kardashian.

\footnotetext{
* Universidade Metodista de São Paulo. Graduada em Filosofia pelas Faculdades Integradas Claretianas e mestranda em Comunicação Social pela UMESP. foxmachado@gmail.com
} 
Figura 1: Stella Maxwell - vestido Moschino.

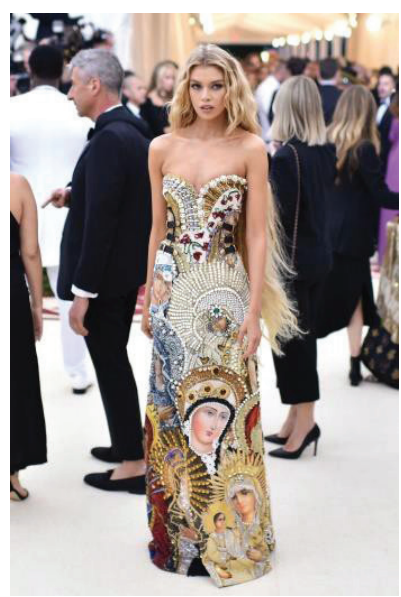

Fonte: https://celebmafia.com/wp-content/uploads/2018/05/ stella-maxwell-met-gala-2018-11.jpg Acesso em: jun. 2019.

Os "looks" usados, incluindo os acessórios e joias, foram selecionados a partir de coleções assinadas por grandes nomes do mundo da alta-costura e que foram influenciados pelas imagens católicas (fig. 2). Os italianos Dolce \& Gabbana, Valentino, Versace e Moschino, mas também o francês Jean Paul Gaultier, o espanhol Cristobal Balenciaga e o inglês John Galliano, de ascendência italiana, dentre outros. Em sua maioria, os artistas têm origem em países católicos.

Figura 2: Trajes desenhados por C. Balenciaga especialmente para um coro católico em 1964.

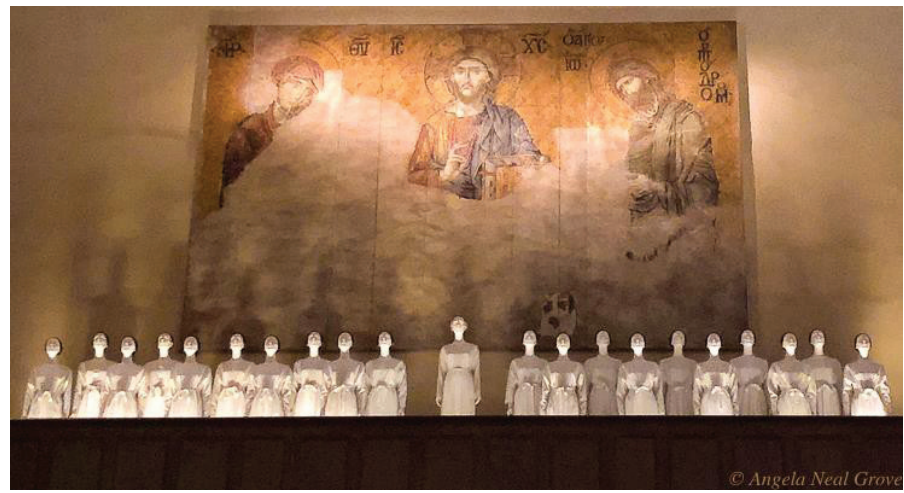

Fonte: https://www.angelanealworld.com/wp-content/uploads/2018/06/ Heavenly-B-Choir-cropped-1-of-1.jpg Acesso em: jun. 2019. 
Contudo, há uma distinção que nos instiga no tapete vermelho do Met Gala 2018. A "teologia" da indústria de entretenimento, parece-nos, é essencialmente focada na divulgação das marcas e dos produtos-celebridades. Nem a religiosidade tampouco a arte são focos nos tapetes vermelhos.

Nosso questionamento relaciona-se à investigação sobre as nuances de um fenômeno midiático que envolve a instituição católica. Em especial, a midiatização de imagens e de símbolos considerados sagrados na exposição Heavenly Bodies. Ademais, interessa-nos também o contexto em que as celebridades - e as marcas usadas por elas - são, aparentemente, os principais objetos de culto.

Em diálogo com os estudos de mídia e religião, do imaginário social, da cultura visual e dos estudos culturais, nossa jornada interpretativa será apoiada pela análise tríplice da a Hermenêutica de Profundidade (HP), cunhada por J. B. Thompson (2011).

Comecemos com uma apresentação dos aspectos mais importantes de Nossa Senhora enquanto integradora dos mundos.

\section{NOSSA SENHORA REINTEGRADORA DOS MUNDOS}

A imagem de Nossa Senhora teria o poder de reintegrar os mundos? Julgamos que sim, pois, além de ser a principal representante do Sagrado relacionado ao Feminino no Ocidente e herdeira simbólico-mítica do arquétipo da Grande Mãe (NEUMANN, 2003), a Virgem Maria transita por muitos mundos e está para muito além das igrejas e altares religiosos tradicionais.

Sua imagem pode ser encontrada nas casas dos mais variados tipos de pessoas; está nas entradas de oficinas mecânicas e de bares; nos adesivos colados nas latarias dos carros e nas capelinhas nas estradas construídas e mantidas por anônimos; está nos pingentes pendurados nos pescoços dos católicos "não praticantes" e também nas tatuagens de homens e mulheres considerados "não tradicionais" e por vezes nem mesmo cristãos. Ela também está nos grafites da arte urbana e na alta-costura, já foi tema de telenovela brasileira e também é a heroína em diversas produções hollywoodianas.

Os limites da capacidade comunicativa de Nossa Senhora são existentes, mas há de considerar que eles são tênues em muitas das vezes. As distinções de classe, de gênero, ideológicas e até mesmo religiosas são inegáveis, mas assim como a água, um importante símbolo da dimensão do Feminino, a Virgem católica, mesmo que represada por alguns preconceitos e as óbvias limitações teológicas, flui pelo imaginário, pelas religiosidades, pela cultura e pelos mais diversos meios de comunicação há séculos. 
ARQUÉTIPO, COMPLEXIDADE E IMAGINÁRIO

Nossa Senhora representa o arquétipo da Grande Mãe. Mas é também a Rainha dos Céus, a Soberana. E é Maria, a heroína humana que, por meio de sua jornada, inspira milhões de mulheres e homens. Complexidade é uma característica que pode ser relacionada à maior representação da dimensão feminina do Sagrado no Ocidente.

São muitos os títulos, denominações e qualidades de Nossa Senhora: é das Graças, da Conceição e da Assunção; é das Dores, dos Aflitos e também da Boa Morte. Ela é de Guadalupe (México) e de Lujan (Argentina); e é também de Lourdes (França) e de Fátima (Portugal). Ela é alva, etérea e silenciosa (Knock - Irlanda) e é também negra, terrena e festiva (Aparecida - Brasil). Ela é do Céu e também é da Terra. Não ignoramos que ela seja um personagem controverso - aliás, isso só reforça a complexidade que apontamos acima. No entanto, em nosso projeto de pesquisa de doutorado, Nossa Senhora é, segundo nossa hipótese, a reintegradora dos mais diferentes mundos.

Ela está no inconsciente coletivo junguiano. Ela transita pelo o que Castoriadis (1987) chama de "magma do imaginário social". Nossa Senhora tem uma capacidade de unir, assim como o imaginário - o "cimento social" denominado por Maffesoli (2003).

Nossa Senhora também é parte do imaginário e da imaginação humana antes mesmo do advento do cristianismo - basta olhar para as imagens das inúmeras deusas de outras mitologias que possuem a mesma iconografia e universo simbólico da Maria católica (fig. 3). Nossa Senhora transita pelo tempo, pelos mitos e religiões, pelas narrativas e também pela cultura, incluindo a cultura midiática.

Figura 3: Isis (Panteão Egípcio) e Maria (Catolicismo)

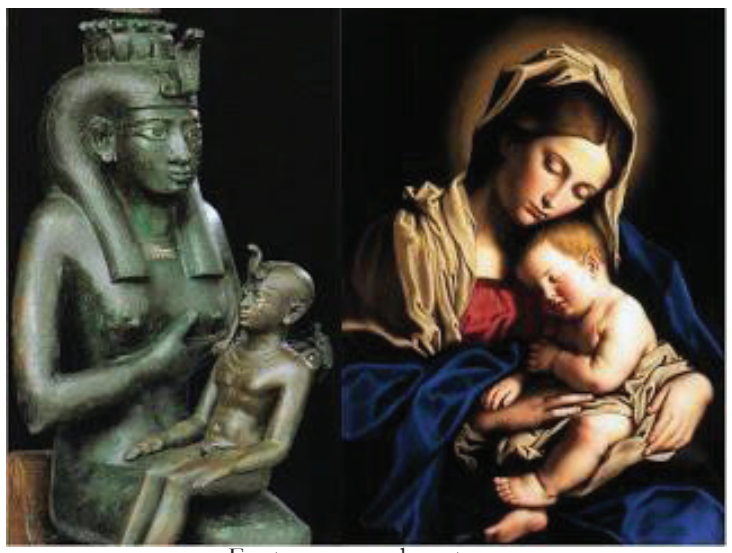

Fonte: acervo da autora. 


\section{SOBRE A IMPORTÂNCIA DOS ESTUDOS DE RELIGIÃO E MÍDIA}

As discussões sobre a religião na mídia são relevantes, pois o número de pesquisas que buscam compreender o tema está aquém da importância dos fenômenos. Jeremy Stolow (2014) reforça o nosso argumento quando diz que, ao ampliar os estudos sobre o assunto, também avançamos na compreensão da própria religião como elemento da vida social humana. Isto é, ele defende que as pesquisas sobre religião e mídia, indo além "do estudo localizado de comunidades, instituições ou atores específicos” (STOLOW, 2014, p. 155), podem expandir o conhecimento filosófico e metodológico a respeito das ciências humanas e sociais.

Isso também se aplica à expansão dos estudos sobre as expressões rituais fora do universo religioso institucionalizado. Stolow aponta que, para além dos limites do controle das autoridades religiosas, é possível perceber "uma profusão global de novas técnicas de aquisição de conhecimento, expressão ritual e auto-cultivo que são cada vez mais realizados em cenas sociais" e que são produzidos “fora dos locais institucionais 'habituais' da prática religiosa, e além do alcance das autoridades religiosas "tradicionais"' (STOLOW, 2014, p. 147). Essas práticas são encontradas nas sendas consideradas alternativas, tais como: dos saberes tradicionais, das terapias complementares e também do entretenimento e da cultura de consumo (STOLOW, 2014).

Ainda sobre as relações entre religião e mídia, Magali do Nascimento Cunha (2016, p.7) destaca que “o 'religioso' (aquilo que é relativo ou próprio da religião) é mediação presente nos diferentes processos comunicacionais midiáticos" e que isso se aplica aos campos jornalístico, literário, musical, publicitário e, destacamos, do entretenimento. Para além do funcionalismo, os estudos de mídia e religião podem abarcar, inclusive, aquilo que "passa pela compreensão das significações imaginárias, das representações socioculturais tanto no processo de produção quanto no de recepção". Ou seja, os fenômenos não religiosos que envolvem a religião.

\section{A IGREJA NA MÍDIA - METAMORFOSE E RELISIÊNCIA}

Francisco, um papa que tira selfies com os fiéis? Fábio de Melo, um padre-cantor com quatorze milhões de seguidores somente em uma de suas mídias sociais? Uma parceria entre o Vaticano e uma exposição de moda no Metropolitan de Nova Iorque? 
Sim, estamos falando sobre fenômenos que envolvem a Igreja Católica, considerada uma das religiões mais tradicionalistas do planeta em muitos aspectos. Porém, quando se trata de sua inserção no mundo da comunicação contemporânea, ela tem se mostrado uma das instituições mais articuladas e sua presença nos processos comunicacionais midiáticos vai para muito além da religiosidade tradicional. Os processos envolvem também o mundo do entretenimento e do espetáculo. Mas como se deu a relação entre a igreja e a cultura midiática? Levando em consideração a nossa escolha metodológica, a contextualização sócio-histórica na estrutura da HP é parte essencial para a compreensão dos elementos simbólico-discursivos na interpretação/ reinterpretação dos fenômenos.

\section{O PROCESSO DE MIDIATIZAÇÃO DA IGREJA}

Recorremos às análises da professora Joana T. Puntel (2011) sobre a "trajetória da Igreja- comunicação" para compreendermos parte das nuances da midiatização do catolicismo.

A trajetória pode ser exposta por meio de fases que envolvem as mudanças de paradigmas históricos, culturais e tecnológicos. Puntel apoia-se também no trabalho de José Marques de Melo para dissertar sobre tais transformações. Partindo da invenção da imprensa e do avanço dos meios de reprodução no século 15 , a postura da Igreja foi se modificando aos poucos. Na primeira fase: o controle, a censura e uma atitude mais defensiva sobre como difundir a informação e o conhecimento. Passando à segunda fase, quando a Igreja se vê pressionada pelas transformações sociais e cede, com restrições e cautela, às novas tecnologias - como o cinema e o rádio. Já a terceira fase é marcada por uma postura de conscientização de que o rádio e a televisão poderiam ser usados como meios de evangelização e de comunicação eclesial. No entanto, foi somente com o advento do Concílio Vaticano II e do (controverso) decreto Inter Mirifica (1963) que a Igreja Católica Apostólica Romana se posicionou afirmativa e oficialmente sobre o uso dos meios de comunicação pela religião para produzir um bem social.

Outros decretos, como o Redemptoris Missio assinado por João Paulo II, foram promulgados no decorrer dos anos seguintes e abordam temas como a necessidade e importância da comunicação social na evangelização e também sobre temas cotidianos, tais como: a preocupação com a difusão da pornografia, da violência e da ética na publicidade.

No início do século 21, são publicados documentos sobre a "Igreja e a Internet" e também sobre a new media, bem como a noção de que a comunicação "refere-se a como relacionar-sem em um 'ambiente' no qual 
estamos imersos e do qual participamos". Toma-se, assim, a percepção de que há "uma cultura, a cultura midiática" e que essa envolve a comunicação social (PUNTEL, 2011, p. 222-232). A análise da professora Joana Puntel se expande, no entanto, limitaremos, por hora, aos pontos levantados até aqui.

Mesmo que resumidamente, optamos por abordar a trajetória da Igreja pela comunicação, pois nosso objetivo é mostrar que, apesar de parte das "profecias" alardeadas durante o século 20 que indicavam a secularização e o fim das religiões, o processo descrito acima nos dá a noção de que as instituições religiosas, em especial a igreja católica, integram um sistema complexo e adaptável e que abrange a sociedade. Bem como, as movimentações no imaginário social.

A religiosidade, assim como a própria natureza da comunicação, é parte da humanidade. É metamórfica; porém, é também resiliente: transforma-se, modifica-se, mas é capaz de manter sua essência intacta. O mesmo valeria para a religião, em especial, para o catolicismo?

Sob a ótica que inclui a identidade nos estudos da religião da cultura, Pierre Sanchis diz que "para continuar a ser aceita, a religião parece ter que entrar em negociação mais benevolente com antigos rivais: economia, política, estética, erótica, apreensão intelectual do mundo" (SANCHIS, 2018, p. 67). Posto isso, não é surpresa que, num mundo de intensa e rápida transformação, a Igreja católica ainda seja uma das maiores instituições religiosas do mundo.

A capacidade de compreender a cultura midiatizada, sem desprezar as questões políticas e dos costumes, parece pesar positivamente na balança de sua sobrevivência. Porém, não podemos nos esquecer de que o catolicismo tem, devido à sua natureza complexa, muitas vertentes e também distintas formas de se comunicar. Para Stig Hjarvard (2012, p. 54), "a sociedade contemporânea está permeada pela mídia de tal maneira que ela não pode mais ser considerada como algo separado das instituições culturais e sociais".

Quando a mídia traz determinadas ordens institucionais particulares para o espaço público, essas instituições são confrontadas com questões sobre a legitimidade das regras e a alocação de recursos de outras ordens institucionais e da sociedade como um todo. Por exemplo, como os estudos nos países nórdicos demonstraram, os meios de comunicação promoveram o contato da religião cristã predominante com os valores seculares da sociedade, o que pode levar as organizações religiosas a modificarem seus valores e comportamentos (HJARVARD, 2014, p. 35). 
A aparentemente inusitada parceria entre o Vaticano e o Metropolitan fortalece a questão levantada por Hjarvard. Ademais, diríamos, incluiu a compreensão sobre a importância da adaptabilidade para a sobrevivência da instituição.

\section{Heavenly Bodies - Imaginário, o Vaticano e os Papas da moda}

A exposição Heavenly Bodies - Fashion and the Catholic Imagination foi produzida pelo Instituto de Moda do Metropolitan Museun of Art (o Met) e aberta em 10 de maio de 2018. A página de apresentação da exposição mostra que a intenção do evento foi a de estabelecer um diálogo entre o mundo da moda e as peças de arte medieval que compõem o acervo do museu de arte sacra (The Met Cloisters). Os ícones e a simbologia bizantina e a ortodoxa também foram incluídas na exposição. Ademais, observa-se a relação contínua entre a moda e a religiosidade católica - incluídas suas práticas e tradições devocionais.

Houve também um diálogo entre o mundo secular e a instituição católica, pois o Vaticano cedeu parte de seu acervo - incluindo alguns itens que nunca haviam saído de Roma. Uma das solicitações do Vaticano foi de que as peças oficiais da Igreja fossem expostas separadamente das peças de alta-costura. Assim, foi montado um setor especial, mais austero, para a exposição das peças (fig. 4).

Figura 4: setor da exposição das peças do acervo do Vaticano

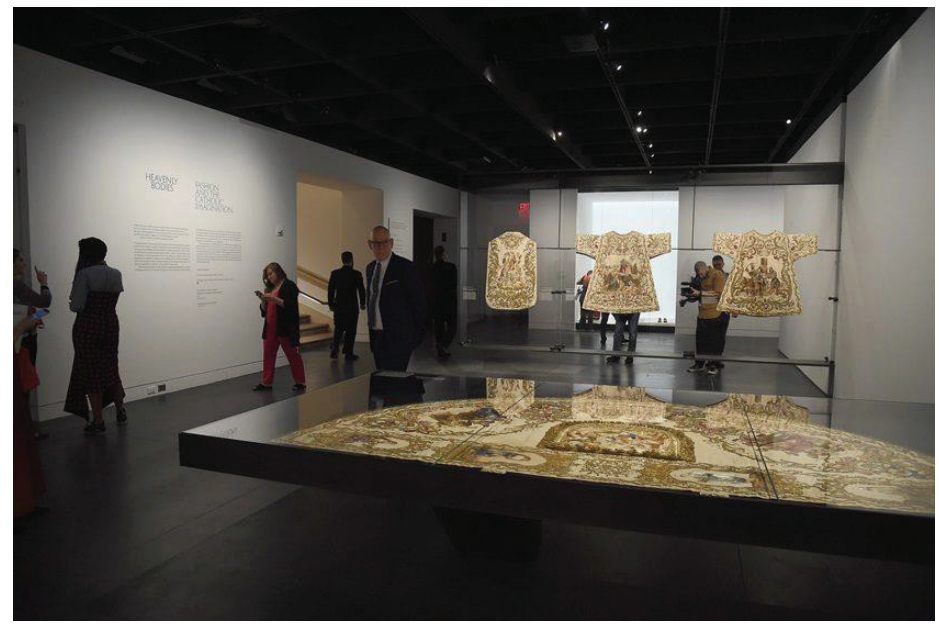

Fonte: https://uploads.metropoles.com/wp-content/uploads/2018/08/25122020/ capa22-840x559.jpg Acesso em: jun. 2019. 
No entanto, a relação entre o Vaticano e a moda não é uma novidade. No artigo The Metaphorical Nature of Creation: Fashion and the Catholic Imagination, Andrew Bolton (2018, s/d), cita duas matérias feitas pelas revistas Newsweek (2005) e Esquire (2007) que proclamavam o Papa Bento XVI como um ícone da moda religiosa por conta de seus mocassins vermelhos (supostamente) feitos pela Prada ${ }^{1}$.

\section{O ENCANTAMENTO NOS OLHOS CATÓLICOS}

"Os católicos veem o mundo através de olhos encantados". A frase de Andrew Bolton (AMERICA, 2018) dialoga diretamente com tema que exploramos brevemente em nossa dissertação de mestrado ${ }^{2}$ e que buscamos aprofundar na jornada do doutorado. As expressões profundamente imagéticas do catolicismo - popular ou institucional - expõem uma das características mais marcantes de uma religião que, apesar das raízes abraâmicas iconoclastas, possui uma relação intrínseca com a imagem.

A larga produção de imaginária de vulto, nos setecentos, tinha explicação no Concílio de Trento, que manteve todas as formas tradicionais de piedade e confirmou, também, o culto às imagens (DELUMEAU, 1973, p. 102; REYCEND, 1786, Conc. Trid., Sessão XXV). A Contra-Reforma e o Concílio deram ênfase à proliferação das imagens como multiplicadoras da própria fé. Elas se faziam presentes sob diversas formas, em todos os espaços religiosos, ou nos espaços de manifestação pública e coletiva de religiosidade, como as procissões (FLEXOR, 2005, p. 165).

É possível enxergar na religiosidade católica a relação íntima e de iconofilia com as imagens e os símbolos, além de uma teatralidade que deixa explícitas até mesmo as raízes arcaicas pré- cristãs do catolicismo. Recorrendo aos estudos da cultura visual, lembramos que:

O aspecto da presença física, do ato icônico, da expressividade ou da performance (força performativa) do símbolo religioso que faz que ele não seja simplesmente ignorado ou tolerado no sentido de uma convivência sem interação:

Bolton diz na entrevista que os sapatos vermelhos de Bento XVI foram feitos pelo designer italiano Andriano Stefanelli. Contudo, verificamos que, apesar de Stefanelli ter presenteado o Papa com um par de sapatos, o sapateiro 'oficial' de Bento XVI é Antonio Arellano, um imigrante peruano que vive em Roma.

2 MACHADO, Patricia Santos. A Mulher além do Bem e do Mal: Malévola e a representação cinematográfica do feminino integrado. 149 p. Dissertação (Mestrado em Comunicação Social) Universidade Metodista de São Paulo, São Bernardo do Campo, 2016. 
símbolos religiosos provocam reações, às vezes, extremas como atitudes idólatras ou iconoclastas, outras vezes, reações mais moderadas, porém ainda intensas, na forma e atitudes iconófilas (RENDERS; ALBUQUERQUE, 2018, p. 178).

O catolicismo, nesse sentido, é uma religião imagética e isso vai muito além das questões teológicas. Aqui estamos considerando a perspectiva do mito, do inconsciente coletivo ou ainda, do imaginário social. Maffesoli (2001, p.76) diz que o imaginário é o que produz a imagem e que "a existência de um imaginário determina a existência de conjuntos de imagens. A imagem não é o suporte, mas o resultado".

Um dos exemplos desse resultado é a visível influência que os elementos católicos presentes no imaginário social têm sobre a criação dos designers de moda que participaram da exposição. Na entrevista concedida por Bolton ao canal oficial da America Magazine - The Jesuit Review do Youtube, ele destaca que tanto a religiosidade católica quanto os designers de moda contam suas histórias e se comunicam por meio das metáforas. Não por acaso, a imagem e a iconografia de Nossa Senhora é a mais recorrentemente identificada nas coleções dos estilistas (fig. 5) e também na exposição (fig. 6).

Figura 5: Criação de Dolce \& Gabbana, Coleção Primavera 2017

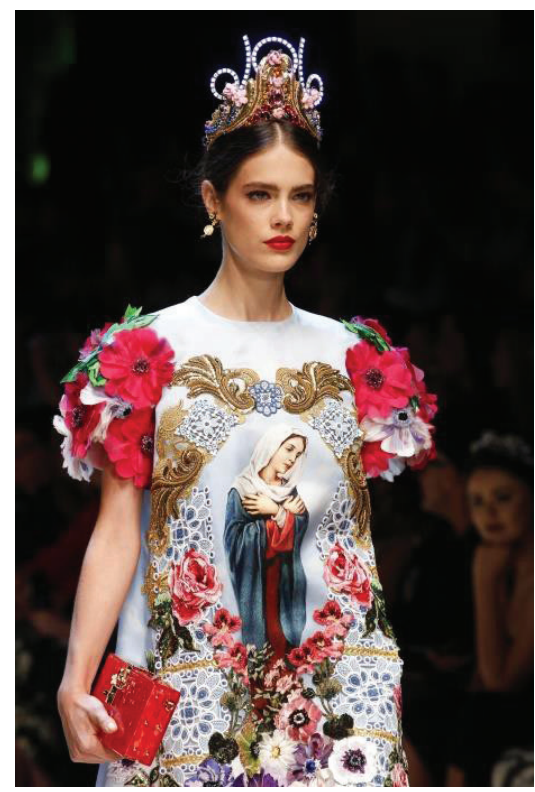

Fonte: https://assets.vogue.com/photos/57e7f6827af31fbd54355214/ master/pass/_ARC0806.jpg Acesso em: jun. 2019. 
Figura 6: Criação de Jean Paul Gaultier em meio às imagens tradicionais. Seção Cult of the Virgin - Heavenly Bodies - The Cloisters Museum, 2018

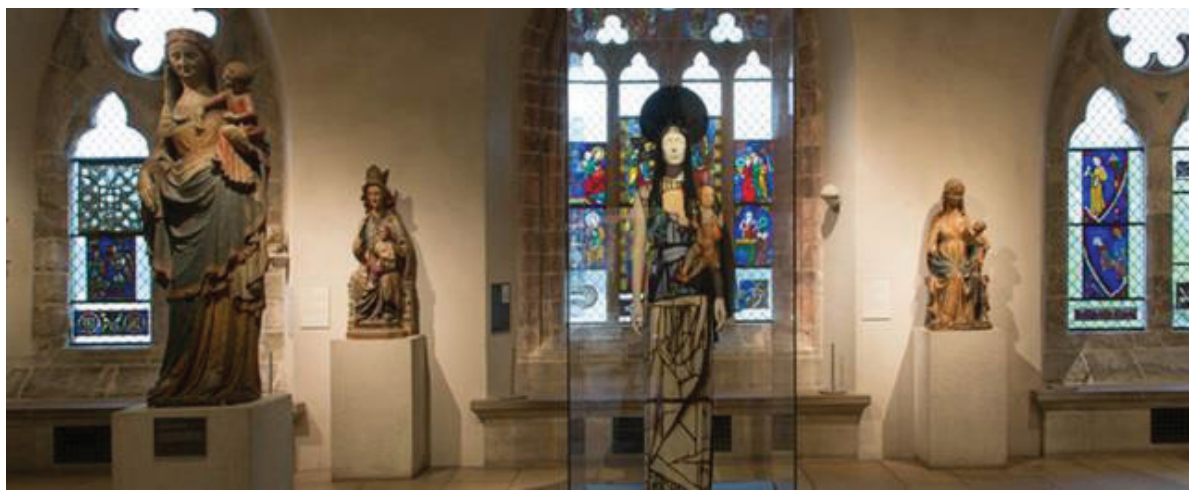

Fonte: https://www.metmuseum.org/-/media/images/exhibitions/2018/heavenly-bodies/exhibitiongalleries $/ 18 . j p g ? \mathrm{w}=720 \& \mathrm{~h}=260 \&$ hash $=374 \mathrm{CA} 5 \mathrm{C} 0 \mathrm{~F} 9 \mathrm{~A} 710889 \mathrm{EF} 4 \mathrm{DD} 50 \mathrm{~A} 12 \mathrm{E} 451 \mathrm{~F} 2 \mathrm{C} 0411 \mathrm{BF}$

Acesso em: jun. 2019.

$\mathrm{Na}$ entrevista coletiva de lançamento da exposição (OLIVEIRA, 2018), Bolton declarou que a moda tanto afirma as lealdades quanto as diferenças religiosas. Ademais, mesmo que a moda não seja considerada um "meio" próprio das ideias de sagrado ou divino, ainda assim o vestuário é essencial quando o assunto é religião.

A declaração de Bolton nos fez pensar sobre os contextos em que essas vestes (e a moda) são usadas/expostas e de como um traje religioso tradicional, ou ainda uma criação de alta- costura, pode ser ligado ao sagrado, ao profano ou, ainda, ligado à dimensão do grotesco.

Salta aos olhos a possibilidade de que a ambientação e a forma com a qual a exposição do Cloisters foi montada tenham resultado numa certa capacidade de sacralização do profano, mais do que numa possível profanação do sagrado.

Dentre as muitas possibilidades do sucesso da Heavenly Bodies, consideramos o contexto em que ela foi apresentada. As roupas criadas pelos designers foram expostas em manequins inanimados (fig. 7) semelhantes às imagens "de vestir" (fig. 8) típicas do século 16 e propagadas, principalmente, pelo catolicismo ibero-americano. 
Figura 7: MET 2018 - Heavenly

Bodies- Fashion and the Catholic Imagination

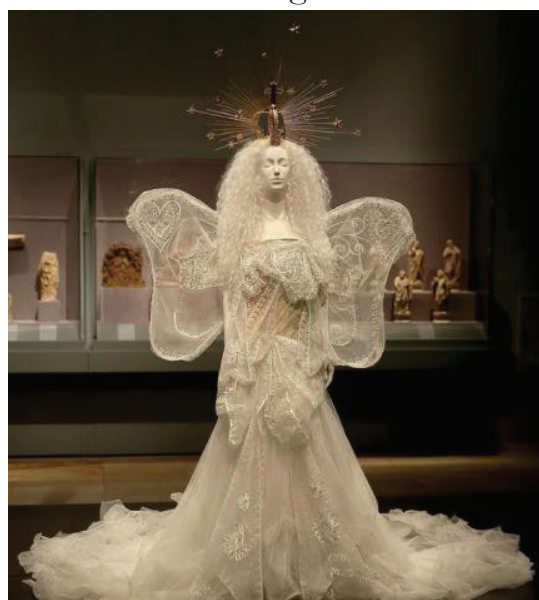

Fonte: https://mondomoda.files.wordpress. com/2018/05/met- 2018-heavenly-bodies-fashion-and-the-catholic- imagination-getty-1.jpg Acesso em: jun. 2019.
Figura 8: Nossa Senhora da Graça - Imagem de vestir ou "da roca" Vale da Pinta - Portugal

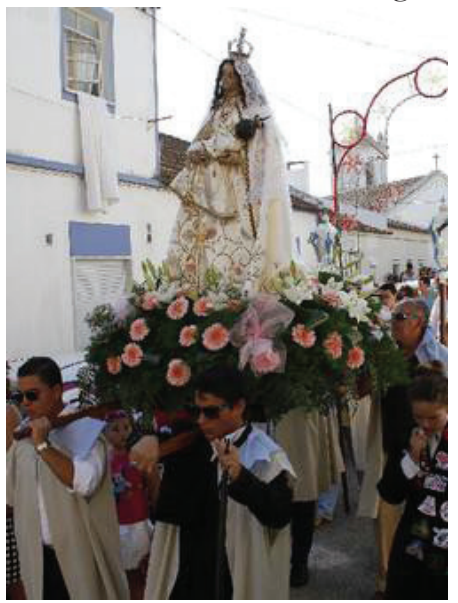

Fonte: http://www.tejoradiojornal.pt/wp- content/uploads/2015/08/nossa-sr-da-Graca.jpeg Acesso em: jun. 2019.

Além disso, o "cenário" da exposição também nos remete ao clima de sacralidade. A estrutura do Met Cloisters foi erigida a partir da incorporação de partes de cinco claustros medievais franceses transportados para os Estados Unidos na década de 1930. Assim, o próprio ambiente, apesar de não ser um templo, é também uma imagem (o resultado) de elementos religiosos presentes no imaginário.

Contudo, convém considerar também que, no catolicismo popular, representar Nossa Senhora ou mesmo outros santos por meio de vestimentas e símbolos sacros faz parte da devoção em algumas ocasiões. Do pagamento de promessas à dramatização de passagens bíblicas, essas práticas, ainda que não oficialmente aceitas pela Igreja, não são por ela condenadas (fig. 9). A tradição é a tal ponto integrada às práticas que até mesmo o a página eletrônicaa oficial do Santuário de Aparecida publicou uma matéria em que é explicada a tradição popular de vestir as crianças como os santos - e também como Nossa Senhora (fig. 10). 
Figura 9: Devotas de Nossa Senhora representando seus títulos

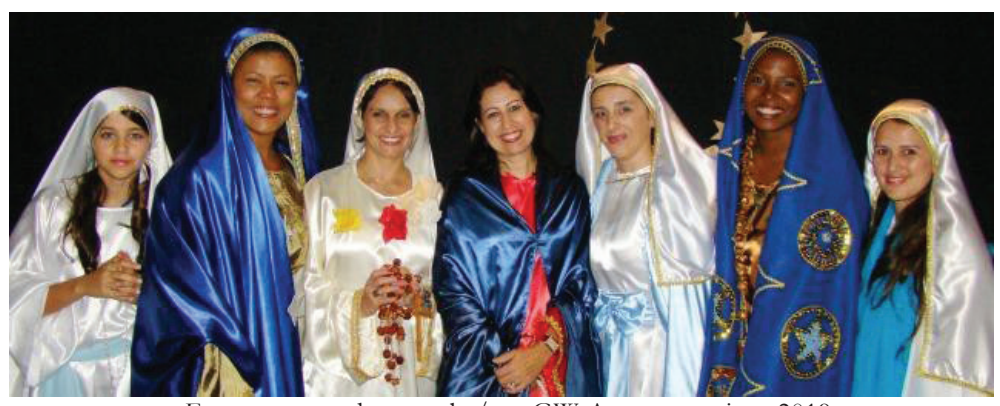

Fonte: encurtador.com.br/qrwGW Acesso em: jun. 2019.

Figura 10: Crianças vestidas como Santo Antonio e N. S. Aparecida

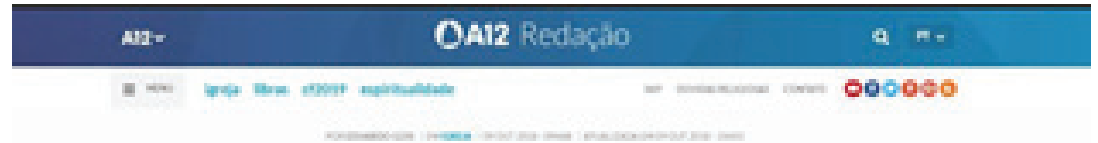

\section{Por que pais vestem filhos pequenos como santos?}

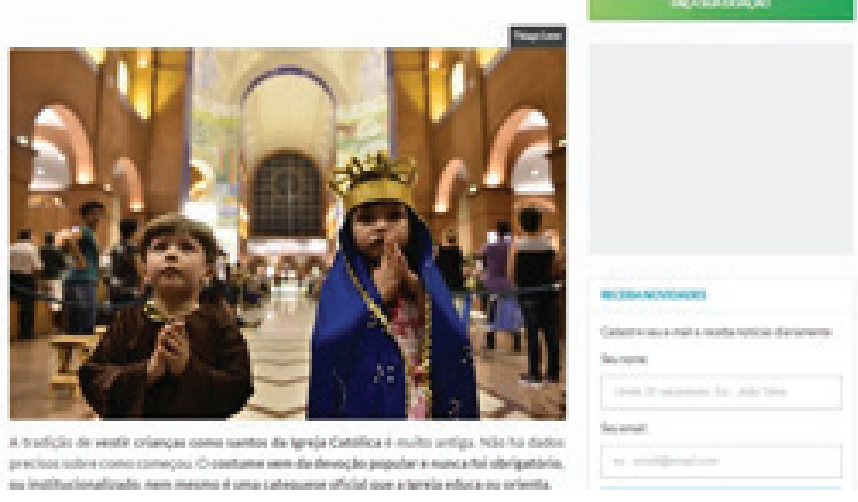

Fonte: print de tela feito pela autora.

A exposição Heavenly Bodies - Fashion and the Catholic Imagination foi um sucesso de público e considerada a mais importante já feita pelo instituto do museu. Mas o baile de abertura da exposição, o Met Gala 2018, foi alvo de protestos de alguns católicos mais tradicionalistas (fig .11) sob a acusação de 'blasfêmia'. 
Figura 11: Protesto liderado pela TFP na abertura do Met Gala 2018
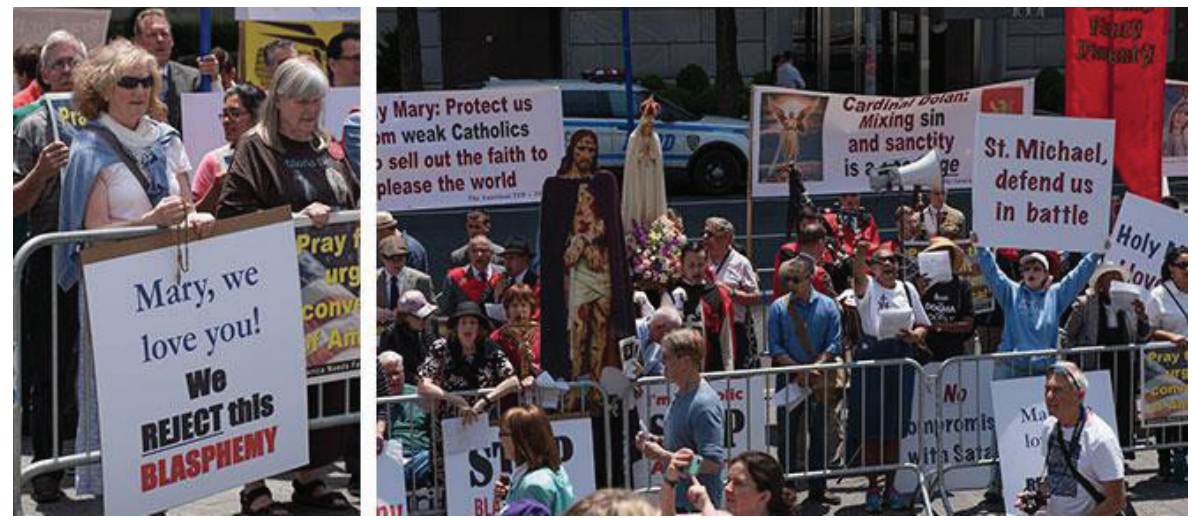

Fonte: https://s3.amazonaws.com/anf-2018/06-Jun/Articles/MET\%20Rally\%20Report/1879-Heavenly-Bodies- Protest_Image-2.jpg Acesso em: jun. 2019.

\section{MET GALA 2018 - O OLIMPO DA CULTURA MIDIÁTICA NO}

\section{TAPETE-VERMELHO}

Considerado o mais importante "tapete vermelho" dos eventos anuais dos EUA, o Met Gala é organizado por Anna Wintour, a "toda-poderosa" da Vogue - desde 1995. O evento beneficente é também conhecido como o "Oscar do mundo fashion" e é uma festa-show em que se constela a união entre o mundo da arte, de personalidades da alta-costura da moda e das celebridades da indústria do entretenimento. Cada uma das edições marca a abertura da exposição anual do Costume Institute, além de arrecadar fundos para o departamento de moda do Metropolitan Museum.

As celebridades mais conceituadas pela indústria e público - e também as efêmeras, que duram apenas uma temporada - desfilam com os trajes confeccionados especialmente para a ocasião. Diferentemente das "imagens de vestir" setecentistas ou ainda das manequins inanimadas da exibição e das crianças vestidas de santo das tradições populares citadas anteriormente, no tapete vermelho do Met Gala 2018, a "contemplação" é outra.

O "culto" e a devoção realizada nos altares das redes sociais são dedicados às celebridades e, principalmente, aos looks por elas usados. As fotos, os memes e as montagens postadas no Instagram ou as hashtags dos 'tts' no Twitter funcionam como ex-votos e a graça alcançada é vibrar com a "vitória" de assistir à diva (deusa) preferida ser laureada com o look mais badalado. $\mathrm{O}$ número de curtidas e compartilhamentos pode definir qual foi a "divindade" 
mais cultuada (fig. 12). Por outro lado, há também uma espécie de manifestação de "mimese" girardiana na penitência daqueles que foram condenados pelos piores visuais ou foram deixados ao silêncio da falta de comentários nas redes e colunas especializadas.

Figura 12: twit de um fã clube da cantora Lana Del Rey

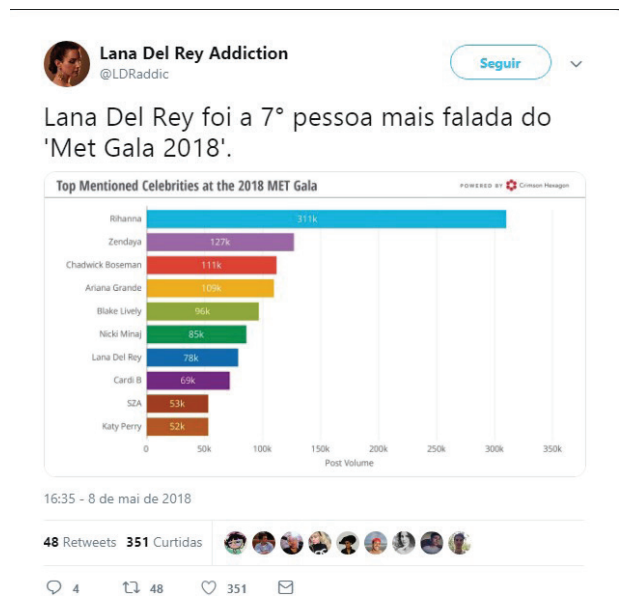

Fonte: print de tela feito pela autora.

Alberto da Silva Moreira (2008) fala sobre um processo de "deslocamento do religioso" como parte das transformações presentes na cultura da modernidade tardia. As instituições ligadas às mais diversas formas de entretenimento - e que fazem parte do que ele chama de "complexo midiático-cultural" - passam a desenvolver as funções que antes eram exclusivas das instituições religiosas.

Mesmo que as roupas usadas pelas celebridades (fig. 13) tenham sido inspiradas pela simbologia católica (fig.14) e criadas pelos mesmos designers, os elementos imaginários, religiosos e culturais sofrem um deslocamento (fig. 15 e 16). 
Figura 13: Lily Collins Nossa Senhora das Dores

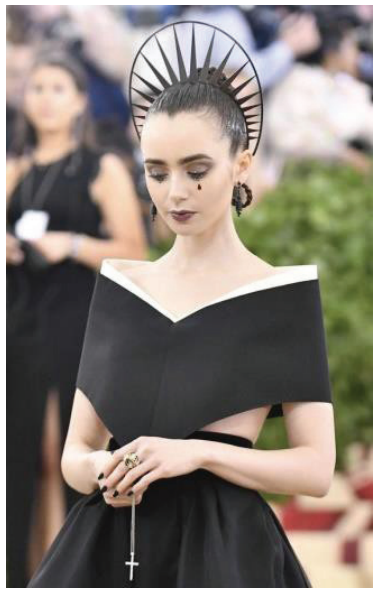

Fonte: https://i.pinimg.com/564x/13/ c5/3a/13c53ab6bb4edfcb13e040f5 00744dc4.jpg Acesso em: jun. 2019.
Figura 14: Nossa

Senhora das Dores

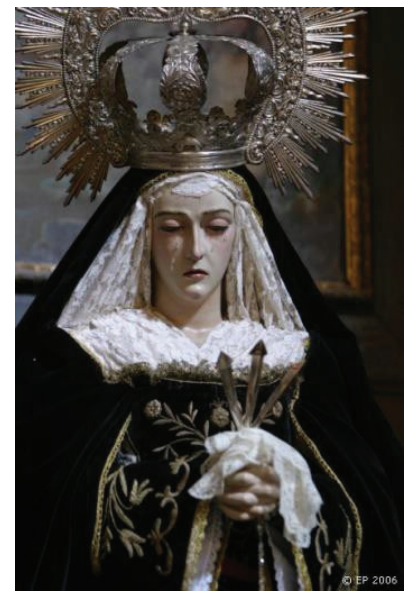

Fonte: http://mediablogs.arautos.org/ifte/files/2014/ 09/Nossa-Senhora-das-Dores.jpg Acesso em: jun. 2019.

Figura 15: interação no Twitter

\section{@28live.7 de mai de 2018}

Lana Del Rey Met Gala 2018 x Seven Swords Piercing the Sorrowful Heart of Mary in the Church of the Holy Cross

6 Traduzir Tweet

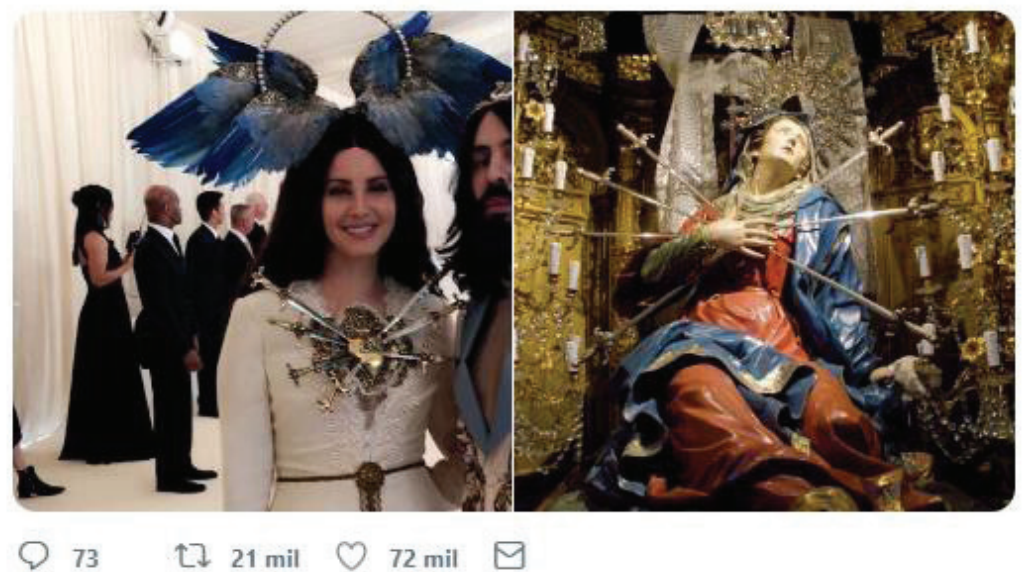

Fonte: print de tela feito pela autora. 
Figura 16: Meme compartilhado com a \#MetGala2018

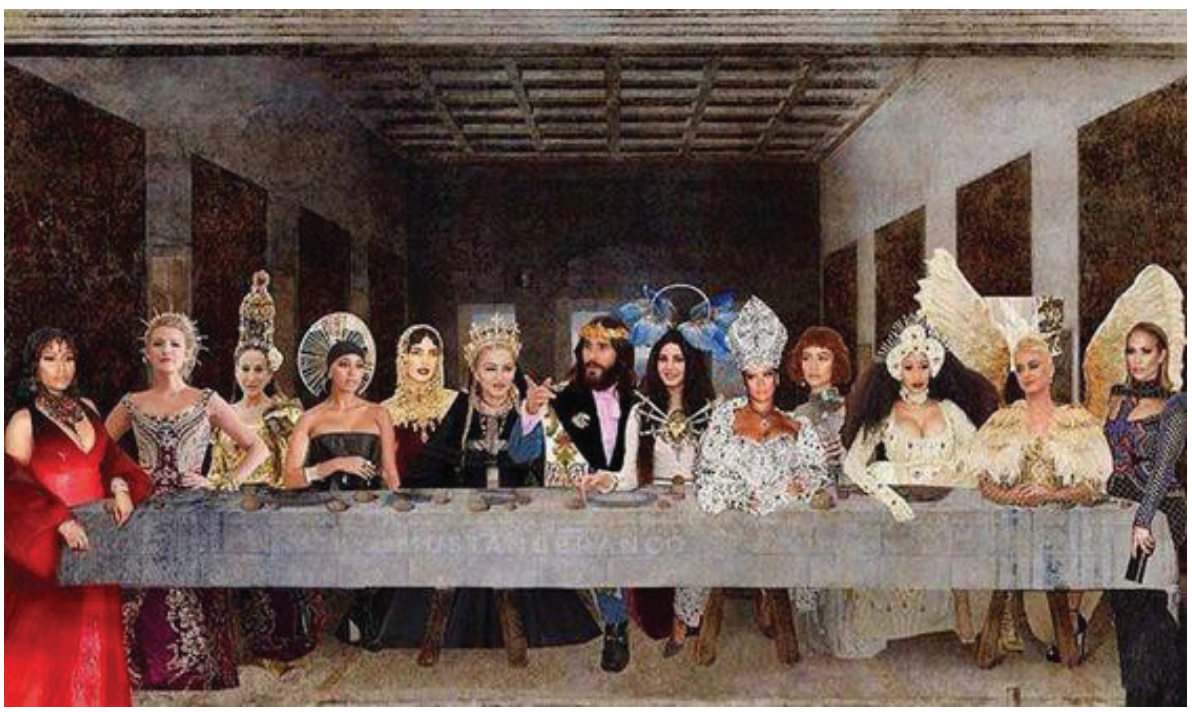

Fonte: https://i.pinimg.com/564x/ed/63/28/ed6328220b78b25da323c8ccfc2fb68e.jpg

Acesso em: jun. 2019.

\section{REFLEXÕES ATÉ O MOMENTO}

Nas palavras de Giles Lipovetsky, “a socialização dos seres por intermédio da tradição, da religião, da moral cede terrenos cada vez mais à ação da informação midiática e das imagens" (2009, p. 193). Não concordamos totalmente com tal análise, pois a ideia de deslocamento nos parece mais adequada que "perda" de terreno. Como falamos inicialmente, se considerarmos o imaginário como o "magma" de Castoriadis ou ainda como o "cimento" societal de Maffesoli, consideraremos também que ele é móvel, flexível e adaptável. A religiosidade, assim como a comunicação, é parte do imaginário. Desse modo, como parte, possui também a mesma natureza maleável. O fenômeno de midiatização da igreja católica também revela tal natureza.

A nosso ver, a parceria estabelecida entre o Vaticano, o Metropolitan Museum e os designers de moda para a realização da exposição Heavenly Bodies parece expressar bem esse deslocamento do religioso, mas de forma resiliente e preservando a essência da religiosidade católica. Algo a considerar é que não foram registrados protestos diretos à exposição em si.

Quanto ao Met Gala 2018, dentre as muitas questões envolvidas, e longe de ser um "incômodo moralista", o que nos provoca é: Qual a natureza mais 
profunda de tal fenômeno midiático? Qual é a expressão cultural e imaginária mais latente? Trata-se do profano sacralizado? Ou do sagrado profanado? Consideramos também: existe um diálogo complexo entre as duas dimensões? Ademais, tais conteúdos imagéticos no contexto em que o evento acontece e as nuances "über-midiáticas" do baile envolveriam também a inserção da discussão sobre o belo e o grotesco - temas que envolvem a religião - nos processos comunicacionais apresentados neste estudo?

Sabemos da complexidade de nossas questões e da inexistência de respostas absolutas. Assim, deixaremos os leitores e leitoras com suas reflexões e essa discussão para nossos estudos futuros. Seguindo o objetivo inicial deste ensaio, o que nos interessa no momento é a investigação sobre a capacidade da imagem de Nossa Senhora transitar pelos mundos e, consequentemente, ser também um meio comunicativo e de reintegração.

\section{REFERENNCIAS}

AMERICA - The Jesuit Rewiew. INSIDE The Met's “Heavenly Bodies” with Curator Andrew Bolton and Fr. James Martin, S.J. 2018. (7m00s). Disponível em: < https://www.youtube.com/ watch?v=jXxmXLrvokk>. Acesso em: 02 de maio de 2019.

BOLTON, Andrew. The Metaphorical Nature of Creation: Fashion and the Catholic Imagination. New York: The Met, 2018. Disponível em: <https://www.metmuseum.org/blogs/now-at-the- met/2018/ heavenly-bodies-fashion-catholic-imagination-introduction $>$. Acesso em: 28 de abr. de 2019.

CASTORIADIS, Cornelius. As encruzilhadas do labirinto. Rio de Janeiro: Paz e Terra, 1987, vol. 3.

CUNHA, Magali do Nascimento. Elucidações contemporâneas nos estudos brasileiros em mídia e religião: a perspectiva das mediações culturais e comunicacionais. Revista Famecos. Porto Alegre, v. 23, n. 2, 2016. Disponível em:

<http://revistaseletronicas.pucrs.br/ojs/index.php/revistafamecos/article/download/22280/14177>. Acesso em: 14 de abr. de 2017.

FLEXOR, Maria Helena Ochi. Imagens de roca e de vestir na Bahia. Revista Ohun, v. 2, n. 2, 2005.

HJARVARD, Stig. Midiatização: conceituando a mudança social e cultural. Matrizes, v. 8, n. 1, p. 21-44, 2014. Disponível em: <https://www.revistas.usp.br/matrizes/article/view/82929>. Acesso em: 20 de abr. de 2019.

Hjarvard, Stig. Mediatization: Theorising the Media as Agents of Social and Cultural Change. Matrizes, v. 5, n. 2, p. 53-91, 2012. Disponível em: <https://doi.org/10.11606/issn.1982- 8160.v5i2p53-91>. Acesso em 20 de abr. de 2019. LIPOVETSKY, Gilles. O império do efêmero: a moda e seu destino nas sociedades modernas. Editora Companhia das Letras, 2009.

MAFFESOLI, Michel. A comunicação sem fim (teoria pós-moderna da comunicação). Revista Famecos, v. 10, n. 20, p. 13-20, 2003. Disponível em: <http://revistaseletronicas.pucrs.br/ojs/index.php/revistafamecos/article/viewFile/3198/2463 > Acesso em: 20 de abr. de 2019. 
MAFFESOLI, Michel. Michel Maffesoli: o imaginário é uma realidade. Revista Famecos, v. 8, n. 15, p. 74-82, 2001. Disponível em: < http://revistaseletronicas.pucrs.br/ojs/index.php/revistafamecos/article/ view/3123/> Acesso em: 20 de abr. de 2019.

METROPOLITAN MUSEUM. Heavenly Bodies: Fashion ant the Catholic Imagination. The Met Cloisters. Nova Iorque: Metropolitan Museum of Art, 2018. Disponível em: <https://www.metmuseum.org/ exhibitions/listings/2018/heavenly-bodies>. Acesso em: 20 abr. 2019.

MOREIRA, Alberto da Silva. O deslocamento do religioso na sociedade contemporânea. Estudos de Religião, v. 22, n. 34, p.70-83, 2008. Disponível em: < https://dialnet.unirioja.es/descarga/articulo/6342547. pdf>. Acesso em 20 de abr. de 2019.

NEUMANN, Erich. A Grande Mãe: um estudo fenomenológico da constituição feminina do inconsciente. São Paulo: Cultrix, 2003.

OLIVEIRA, Jorge Marcelo. MET 2018: confira algumas peças da exposição 'Corpos Celestes: Moda e Imaginação Católico’. Mondomoda. 07 maio 2019. Disponível em: <https://mondomoda.com. br/2018/05/07/met-2018-exposicao/>. Acesso em: 27 de abr. de 2019.

PUNTEL, Joana T. A IGREJA A CAMINHO NA COMUNICAÇÃO. Teocomunicação, Porto Alegre, v. 41, n. 2 p. 221-242, jul./dez. 2011. Disponível em: <https://core.ac.uk/download/pdf/25529639.pdf>. Acesso em 29 de abr. de 2019.

RENDERS, Helmut; ALBUQUERQUe, Ana Lídia de. Cruz e Chamas como logotipo, ornamento, arte litúrgica e símbolo religioso. Estudos de Religião, v. 32, n. 1, p.159-190, jan.-abr. 2018. ISSN Impresso: 0103-801X - Eletrônico: 2176-1078. Disponível em: < https://www.metodista.br/revistas/revistas-ims/ index.php/ER/article/download/8475/6230>. Acesso em: 02 de abr. de 2019.

SANCHIS, Pierre. Religião, cultura e identidades - Matrizes e matizes. São Paulo: Editora Vozes, 2018.

STOLOW, Jeremy. Religião e Mídia: notas sobre pesquisas e direções futuras para um estudo interdisciplinar. Religião e sociedade [online], vol.34, n.2, p.146-160, 214. Disponível em: < http://www.scielo. br/pdf/rs/v34n2/0100-8587-rs-34-02-0146.pdf>. Acesso em: 14 de abr. de 2019.

THOMPSON, John. Ideologia e Cultura Moderna. São Paulo: Vozes, 2011. 